\title{
A Histopathological Study of Multiple Myeloma
}

\author{
By \\ Mizu Kojima and Yoshio Kamejima \\ Department of Pathology, Tohoku University School of Medicine, \\ Sendai; Director: Prof. Dr. K. Akazaki
}

(Received for publication, May 12, 1960)

\section{INTRODUCTION}

The first case report of multiple myeloma was published by Watson and Bence-Jones in 1845 and since then the disease has been the theme of many studies $^{1-5)}$. But the studies on this tumor were mostly centered on morphological or biological researches on the tumor-constituting cells, inquiries into the general pathology of the disease being relatively rare. So, the present authors undertook elucidation of the pathological characteristics of this disease and with the outcome as starting point, attempted a study on its essential nature. The results obtained were as reported in the following.

\section{MATERIALS AND METHOD}

As materials, 13 cases of multiple myeloma and 1 cases of plasma-cell leukemia autopsied at the Pathological Laboratory, Tohoku University School of Medicine between January 1954 through June 1959, and a case of plasmacell leukemia autopsied at the Pathological Laboratory, Fukushima Medical College in 1953, 15 cases in total. These samples were prepared into paraffin blocks and frozen specimens in the routine manner, stained by various methods and subjected to histopathological examination.

\section{RESULTS}

I) On the tumorous pathological changes.

1) Changes in the osseous system.

i) Scope of tumorous proliferation.

In this disease, we can observed a systematic tumorous proliferation in the bone system in an incomplete way. The tumorous proliferation and the bone resorption tended to be more active in the flat bones, including the ribs, the sternum, the skull and the pelvis, than in the long bones. Among the long bones, the activities were stronger in the upper than in the lower libms. This tendency of stronger proliferation in the flat bones is well consistent with the opinion of

小島 瑞, 重島義男 
Anderson ${ }^{6}$ who took the red marrows to be the preferred site of occurrence of this type of tumor.

ii) Mode of proliferation of the tumor.

The tumorous proliferation consisted in nodular proliferation mixed with lenkemic diffuse proliferation, in varying ratios according to the case and the site. Among the materials of the present study, nodular growth predominated in 8 cases and diffuse growth took the lead in the other 7 cases including the 2 cases of plasma-cell leukemia. In the nodular proliferation foci, however, distinctly definite boundaries were only rarely to be seen around the nodules, which were more often surrounded by diffuse growth. In some cases of leukemic proliferation, too, the part of dense-packed cells strongly resembled nodular proliferation foci. Unequivocal diffuse growth could be observed only in one of the plasmacell leukemia cases. The process of tumor cell proliferation is traceable by silver staining. Argyrophil fibres are scarcely observable among the nodules and the general appearance is that of a cancer. As the nodules begin to proliferate infiltratively into the surrounding tissues, the argyrophil fibres come to show gradual increase, and often the individual tumor cells are eventually entwined in fine argyrophil fibres.

iii) Destruction and resorption of bone tissues.

Pictures of destruction and resorption of bone tissues were apparent in nearly all the cases. By grades, these could be classified into 7 severe-graded cases, 4 moderate-graded cases, into 3 mild-graded cases and 1 nearly negative case (of plasma-cell leukemia). The frequency of pathological fractures of bones is given by Bayrd and Heck' as $16 \%$, by Carson et al. ${ }^{3 \prime}$ as $55 \%$ and by Snappers et $a{ }^{\circ}{ }^{\circ}$ as $62 \%$. Among the present authors' subjects, 9 cases (60\%) showed such fractures, most frequently in the ribs (5 cases), next in the vertebrae (4 cases), in the sternum and the ulna in 1 case each. Multiple pathological fractures in the same case were frequent in the ribs, and in the vertebrae the fracture preferentially came forth in the lower thoracic or lumbar vertebrae, involving paraplegia and in turn causing ascending pyelonephritis.

In this disease, the extraordinarily active resporption of the bone tissue in spite of the not very intense destructive proliferation, less intense than in other malignant tumors, and the absence of reactive osseous or osteoid formation in the site of bone resorption are probably very specific findings of this disease.

iv) Myeloma cells.

The cells constituting myeloma show rather wide morphological variability by cases and by sites, but after all, they belonged to the so-called plasma-cell type myeloma in all our cases. The tumor cells varied rather notably in size but their nuclei usually stood eccentric, were rich in chromatin, were nearly always found containing nucleoli under methylgreen-pyronin staining and their 
protoplasma were pyroninophil. Russel's bodies were very rare, but often violet granules were found accumulated under Weigert's fibrin staining. Bi- or trinuclear cells were rather frequent and on some occasions polynuclear cells with half a dozen nuclei were observable. Nuclear division was detected far less frequently than anticipated, and abnormal division of nuclei could not be definitely demonstrated.

v) Intercellular substances in the tumor.

Varying quantities of argyrophil fibres and collagenous fibres could be found among the tumor cells. Besides, the stroma contained more or less large accumulations of eosinophilic amorphous substances and comparatively rarely of bleeding. The amorphous substances stained red-violet or violet by Weigert's fibrin stain, was pyroninophil under methylgreen-pyronin staining, stained red under PAS staining and sometimes showed metachromasy under gentiana-violet staining, but only in low degree. Such amorphous substances were relatively scanty in the sites of active tumor-cell proliferation but could be often found in the herds of tumor cells more or less advanced in degenerative process. Such tumor cells in degenerative process gradually come to show staining behaviors similar to the amorphous substances above and in new necrotic foci, the amorphous substances take the form of granules. In such a form, these substances show semblance to the necrotized and destroyed cell bodies, so that it may be inferred that at least a part of the intercellular amorphous substances originate in the tumor cells themselves. These amorphous substances probably flow about in random direction within the tumor tissues, taking the form of myelin, and often encircling the blood vessels, show circular formation. Sometimes, the picture of their penetrating through the vascular walls and invading the lumina.

2) On the extramedullary dissemination of the tumor.

i) Continuous extention of the tumor

The tumor tissues outside the bone-marrows were mostly found around the bone. These places nearly correspond to the sites where bone trabeculae were strongly destroyed by intramedullary tumor tissue, or to the pathologically fractured sites. And most of the tumor tissues around the bone have macroscopically evident nodules, sometimes showing a lump of tumor of the size of a baby's head. On the other hand, the tumorous proliferation around the bone rarely takes place at the sites where the tumor has the tendency to diffuse proliferation.

ii) Distant metastasis.

The distant metastasis of this tumor was found in 9 cases $(60 \%)$ among 15 , and it was found mostly in the liver ( 6 metastatic cases), the spleen ( 7 metastatic cases) and in the lymph nodes (7 metastatic cases) as Churg \& Goldon ${ }^{10)}$ and Hino ${ }^{11}$ pointed out. Besides, also in the testis, the subcutaneous tissues, the 
muscles, the dura, the kindney and the suprarenal body etc. metastatic foci were observed. This distant metastasis of the tumor, differing from its continuous extension, is seldom observed by macroscopic examination, but mainly found by histological research. Myelomatic cells appeared in peripheral blood in 12 cases $(86 \%)$ among the 14 cases examined. The frequency of their appearance was usually below $10 \%$ of the lecoucyte count, except in the two cases of plasmacell leukemia.

II) On the pathological changes based on paraprotein.

In the lymph nodes: Perceptible swelling was not at all seen in any of the case examined, the lymph nodes being rather atrophied. The chief changes in this part are sinusreticulosis and especially the proliferation of reactive reticulum cells at the marginal sinus.

In the liver: A degenerative picture of the parenchyma of liver was seen only in 1 case. The Kupffer's stellate cells within the sinusoid were generally swollen, but their reaction process against paraprotein was not distinct because of the large quantity of hemosiderin they had taken up.

In the spleen: Except the cases in which metastasis of the tumor was found, the spleen was atrophied and the lymph follicles were remarkably reduced. The central arteries were in most cases thickened and especially their inner walls displayed fibrous or hyaline degeneration and thickened. These sites show the same attitude against stains as the tumorous intercellular amorphous substance. In the medullary cord the multiplication of round reticulum cells and reactive plasma cells was often observed together with the increases of the fiber elements.

In the kidney: Usually the kidney had gained a little in weight, and has a peculiar luster. In three cases the kidneys suffered from either pyelonephritis or renal abscess. It was only in 1 case that the infiltration of tumorous cells into the kidney was observed. The change in the glomerules is usually mild, as Allen ${ }^{12)}$ has stated, consisting only in swelling or in slight thickening of the basal membrane. In the urinary tubules, particularly in the lower ones, a great many protein casts were not seldom. The staining behavior of these casts was similar to the above-mentioned intercellular eosinophilic substance in the tumor, but the stainability of the casts themselves differed not a little owing to the difference of their location within urinary tubule and of the stratified construction which they often present. The tubular epithelium near the casts began to muliply actively as soon as they fell into destruction and degeneration, forming polynuclear cells resembling (foreign giant cell) around them. The urinary tubules, particularly the upper ones, were not seldom atrophied or swollen edematously. In the stroma, an invasion of eosinophilic substance and infiltration of cells were observed. Bell ${ }^{13}$ stated that he saw protein casts in 7 cases among 11 , 
while the present authors saw them remarkably formed in 6 cases, moderately in 2 cases, and slightly or negatively in 8 cases.

In the lung: The walls of the interlobular blood vessels in the lung were more or less swollen and expanded, sometimes showing fibrous degeneration. In some cases the lumen was remarkably narrowed on account of the thickening of the blood vessel wall. The same change was found also in the alveolar wall: An amorphous substance that shows the same staining behavior with the previously described intercellular amorphous substance in the tumor was found accumulated in the alveolar walls and flowing out into alveolar lumens often to form hyaline membranes. Also the alveolar walls were found fibrously thickened and in the sites where they ware swollen nodularly they sometimes take the form of Masson's body. Where the pulmonary stroma was fibrously thickened the lung tissue formed irregular atelectasis, and in the other regions compensative emphysema was observable. Often the exsudative fluid that stained comparatively light was reserved in the alveolar lumen, and such an exsudation was highly accelerated by infection. In this case the frequency of complication with pneumonia is known to be high as Snapper') etc. indicated, and also in this present research the complication was seen in 8 cases $(53 \%)$. Thus, the exsudation is widespread even in the foci in which cellular infiltration is mild.

III) On the complicated pathological changes.

Calcification was seen in the kidney (14 cases), the lung (8 cases) and the liver ( 3 cases) etc. and was generally mild except in two cases of calcification in the lung. The degree of the calcification did not necessarily have a definite relation with that of destruction or resporption of bone.

Hemosiderosis was chiefly found in the liver and the spleen, especially severely in the latter. Seeing that the hemosiderosis was the severer, the larger the quantity of transfusion, this is deemed to be due to transfusion.

\section{DISCUSSION}

It is known that there are cases in which leukemic diffuse growth is seen besides the cases that show nodule formation, in the tumorous cell proliferation in multiple myeloma (Heilmeyer) ${ }^{14}$. According to the findings of this present studys, it is rare that a case shows either nodular growth or diffuse proliferation alone, for both the types of proliferation are found mixed in most cases. Then, why the nodular growth and the diffuse proliferation are observable in the proliferation of this tumor? Though scarcely any explanation has been presented as yet on the cause and reason, the present authors are inclined to find the answer in the nature of the tumor cells. The reason shall be stated in the 
following.

Though many theories are being presented with regard to the form of tumor cells, they may be roughly divided as follows:

1. Plasma-cell theory (including that of undifferentiated cells).

2. Blood parenchyma-cell theory (of myeloblasts, myelocytes, Iymphocytes, erythroblasts etc.).

The blood parenchyma-cell theory was predominant while the form of the tumor cell had been observed by tissue specimen, but by the advance of hematocytological research, especially with the prevalence of sternal puncture the plasma-cell theory, first advocated by Wright ${ }^{15)}$ and supported by Diggs et al. ${ }^{16}$ ) and Bayrd et al. ${ }^{17)}$, came to be regarded with great importance. As already stated, all the cases the present author studied were of the plasma-cell type myeloma. Although there are many theories such as the blood-cell theory ${ }^{18)}$, the reticulum-cell or the reticuloendothelium theory ${ }^{17,19)}$ and the theory of transformation of blood-vessel adventitial cells ${ }^{20)}$ as for the origin of the plasma cell, yet no convincingly definitive conclusion was obtained so long as the present authors' experiments and researches go. Only, seeing the facts that this tumorous proliferation was confined within the bone tissues and that extramedullary proliferation was remarkably milder than the former proliferation, it will safely be concluded that the mother-cells of this tumor exist in the medullary tissue. However, whether this cells are still in the state of blood cells or of tissue cells, the opinions are still divergent. The present authors should rather like to regard the controversy to be a direct reflexion of the nature of the plasma cells. That is, the plasma cells are considered originally to have both the characters of blood cells and tissue cells. If the matter is viewed from this point, it will easily be understood that the nodular growth and the diffuse proliferation do appear simultaneously in the process of this tumorous proliferation. The tumor cells and the mode of proliferation of the 13 cases of multiple myeloma and the 12 cases of plasma-cell lenkemia were studied and it was found that the two are intrinsically the same disease, leading to the following inference : in plasma-cell leukemia the blood cell character alone is emphasized out of the two characters of the tumor cells, while in the multiple myeloma both the two characters are mixed positively in various ratios.

The other greatest characteristics of this tumor are the invasion of paraprotein into each organs that appears accompanied by the tumorous cell proliferation, and the tissue reaction following it. Infering from histological researches, a certain substance released by the secretion or destruction of the tumorous cells, entering directly or through the lymph way into the blood road, seemed to cause the paraproteinemia. Pathological renal changes are well known as pathological changes cuased by paraproteinemia, but looking through the present authors' 
findings pathological pulmonary changes should also be considered seriously as well as the pathological renal change. In the kindney, the reaction based on the appearance of paraprotein substance in the urinary tubules layed the leading part. As far as the authors' findings tell, the frequency of the appearance of Bence-Jones protein bodies in urine seemed to go parallel with the degree of the pathological renal change. A certain correlation between the protein content of serum and the pathological renal changes, however, could not be found. In the lung, it was ascertained that paraprotein was accumulated on the alveolar walls owing to the disturbance of the blood vessel system, then it flowed out into the lumina in which it was gradually organized as long as the flowing continued, causing peculiar atelectasis and compensatory emphysema.

\section{CONCIUUSION}

The author made histopathological researches of 13 cases of multiple myeloma (plasmacytoma) and 2 caes of plasma-cell leukemia and obtained in summary the following results.

1) The proliferation of this tumor is confined solely in the bone-marrows and, though inperfectly, is systematic.

2) Nodular proliferation and diffuse proliferation were seen in the process of proliferation of this tumor. These are considered to be based on the characters of plasma cells which have the two characters, of blood cells and of tissue cells.

3) The destruction and the resorption of bone by the invasion of tumor are exceedingly remarkable, while reactive bone proliferation is absent.

4) Appearance of eosinophilic amorphous substance accompanying the proliferation of argyrophil fibres and the destruction and necrosis of cells are observed among the tumor cells.

5) The tumor cells bear closest resemblance form to intra-medullary plasma cells. Their origin, however, is not clearly explained by the authors' present researches.

6) The dissemination of the tumor cells towards outside the bone marrows is mainly consists in continuous extension, preferrably forming nodes around the bone. The tumor cells are detected in the peripheral blood in most casses though in a small scale, and sometimes form relatively localized metastatic foci in the liver, the spleen, the lymph nodes, the testes, the subcutaneous tissue and the muscles etc.

7) The pathological change caused by paraprotein is remarkable in the blood vessels of the whole body, especially, in those of the kidney and the lung. a) In the kidney, the chief changes are the formation of protein casts inside the urinary tubules and the reaction accompanying it. b) In the lung, the invasion of paraprotein into the alveolar walls and the alveolar lumens, and the formation of peculiar atelectasis and compensatory emphysema due to the variation and 
the organization of the paraprotein are observed.

8) Besides, calcification and hemosiderosis are occasionally noticed as complicating pathological changes.

\section{References}

1) Kahler, O., Prag. med. Wschr, 1889, 14, 45.

2) Geschickter, C.F. \& Copeland, M.M., Arch. Surg., 1928, $16,807$.

3) Lichtenstein, L. \& Jaffe, H.L., Arch. Path., 1947, 44, 207.

4) Wurmann, F. \& Wunderly. C., Die Eiweisskörper des Menschen. 2 Aufl. Benno. Schwabe Basel, 1952.

5) Sugano, H., Acta path, Jap., 1959, 9, 217.

6) Anderson, W.A.D., Pathology. 3 ed. St. Louis, Mosby, 1957.

7) Bayrd, E.D., \& Heck F.G., J.A.M.A., 1957, 133. 147.

8) Carson, C.P., Ackerman, L.V. \& Maltby, J.D., Amer. J. Clin. Path., 1955, 25, 849.

9) Snapper, I., Turner, L.B. \& Moscowitz, H.L., Multiple Myeloma. Grune \& Stratton, 1953.

I0) Churg, J. \& Gordon, A. J., Amer. J. Clin. Path., 1950, 20, 934.

11) Hino, S., Gan no Rin., (Japanese) 1955, 1, 531.

12) Allen, A.C., The kidney, medical \& surgical disease. Grune \& Stratton, 1951.

13) Bell, E.D., Amer. J. Path., 1933, 9, 393.

14) Heilmeyer, L. \& Begemann, H., Handbuch der inneren Medizin, 2 Bd. Blut \& Blutkrankheiten. 4 Aufl. Springer, Berlin, Heidelberg, 1951.

15) Wright, J.H., referred to 9) Snapper et al. Multiple Myeloma, N.Y. Grune \& Stratton, 1953.

16) Diggs, LW. \& Sirridge, M.S., J. Laborat. Clin. Med., 1947, 32, 167.

17) Bayrd, E.D., Blood., 1948, 3, 987.

18) Naegeli, O., Blutkrankheiten \& Blutdiagonstik. 5 Aufl. Berlin, Springer, 1931.

19) Rohr, K., Das menschliche Knochenmark. Georg Thieme, Leipzig. 1940.

20) Amano, S., Acta haem. Jap., (Japanese) 1946, 9, 25.

21) Apitz, K., Virchows Arch., 1940, 306, 631. 
Plate I. Smear specimen of bone-marrow puncture: The tumor cells are almost round and comparatively small. The nucleoli are conspicuously large. The protoplasm is coarse and comparatively little in quantity. (Giemsa staining).

Plate II. Histological picture of the femoral marrow: The tumor cells are growing up into nodular shape. (H-E staining).

Plate III. Histological picture of the sternal marrow: The tumor cells are proliferating leukemically and diffusely. ( $\mathrm{H}-\mathrm{E}$ staining).

Plate IV. Histological picture of the sternal marrow: The tumor colls, infiltrated into the osseous substance, are actively destroying and resorbing the osseous substance. Reaction of the bone tissue against them is not seen at all. (H-E staining).

Plate V. Histological picture of a metastatic herd of the left hypogastric tumor: Conspicuous is the grotesque figure of the necrotic substance which is in the shape of myeline or wheel. The central part of the wheel-shaped constructions is mostly taken up by the lumens of blood vessels. (H-E staining).

Plate VI. Histological picture of a tumor in a rib: The increase of the argyrophil fibres is remarkable. Some of them are connected with one tumor cell each. (Pap's silver staining).

Plate VII. Histological picture of a tumor in the liver: Tumorous nodules are seen in the lobules. (H-E staining).

Plate VIII. Histological picture of a urinary tubule: The protein casts inside the tubule condensed into a lump, cells of a part of the tubular epithelium round the lump becoming giant cells. In the urinary wall in that part destruction of the epithelial cells is seen. ( $\mathrm{H}-\mathrm{E}$ staining).

Plate IX. Histological picture of the lung: The alveolar wall is nodulatedly thick on account of the pile of amorphous substanec. (H-E staining).

Plate X. Histological picture of the surroundings of pneumonia: Evident invasion of paraprotein into the alveolar lumina. ( $\mathrm{H}-\mathrm{E}$ staining).

Plate XI. Histological picture of the central artery of the spleen: The arterial wall is remarkably thickened and the invasion of paraprotein is noticeable in its wall. $\mathrm{H}-\mathrm{E}$ staining).

Plate XII. Histological picture of the lung: Conspicuous calcification of the alveolar wall. (H-E staining). 


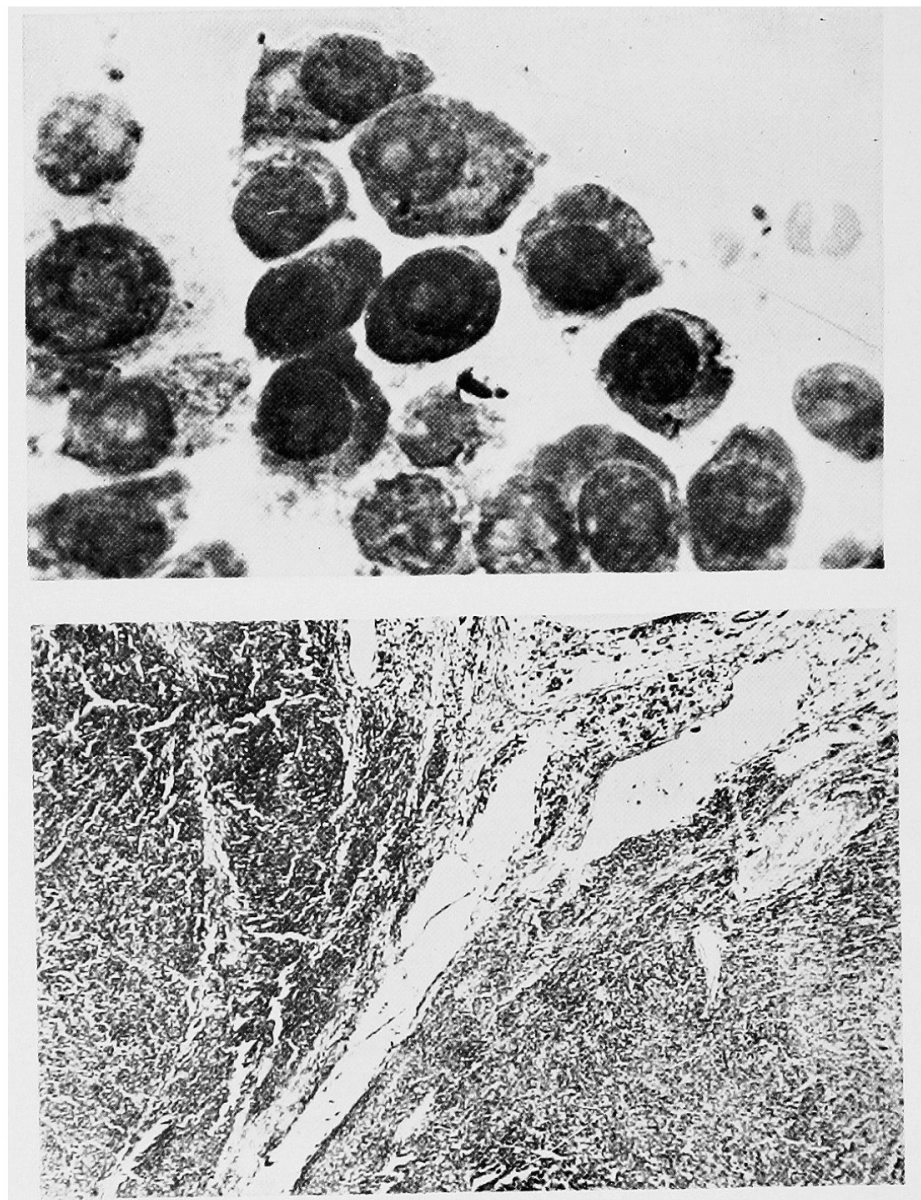

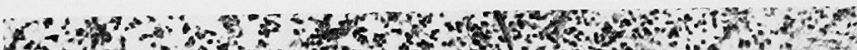

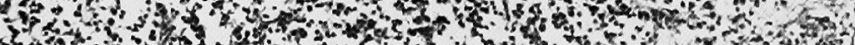
s.

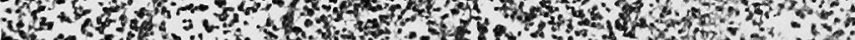

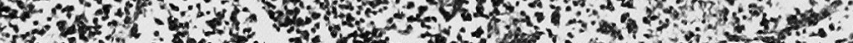

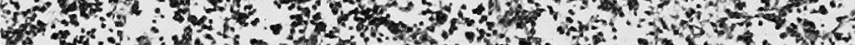

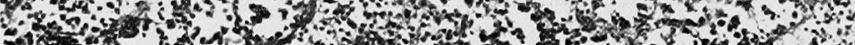

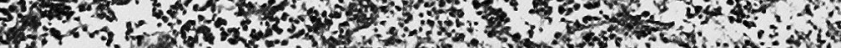

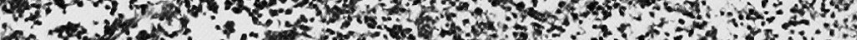

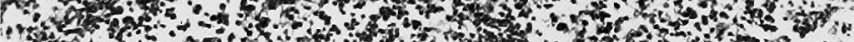

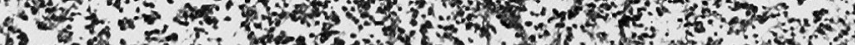

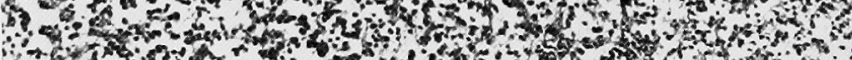

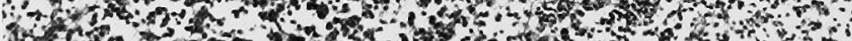

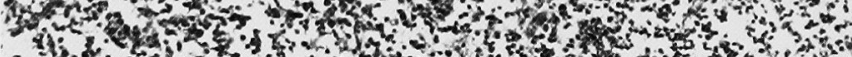

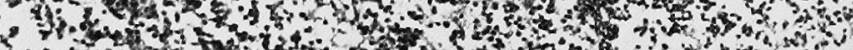

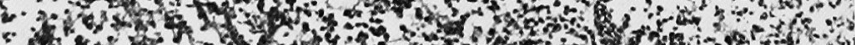

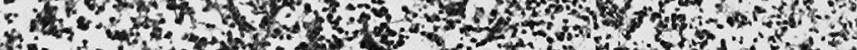

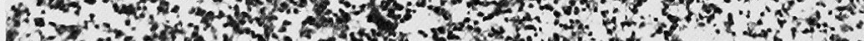
Fon 0 .
Plate I

Plate II

Plàte III 


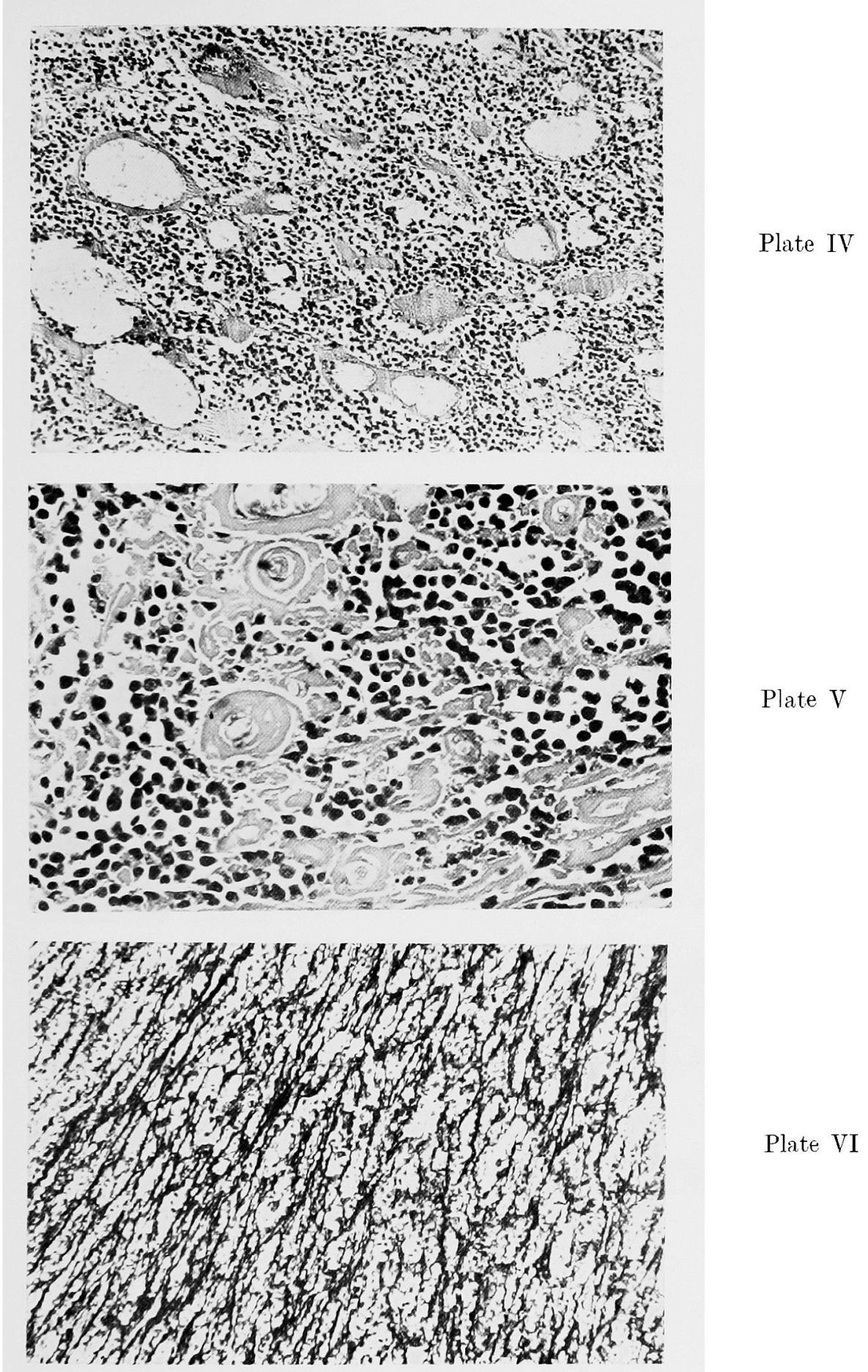




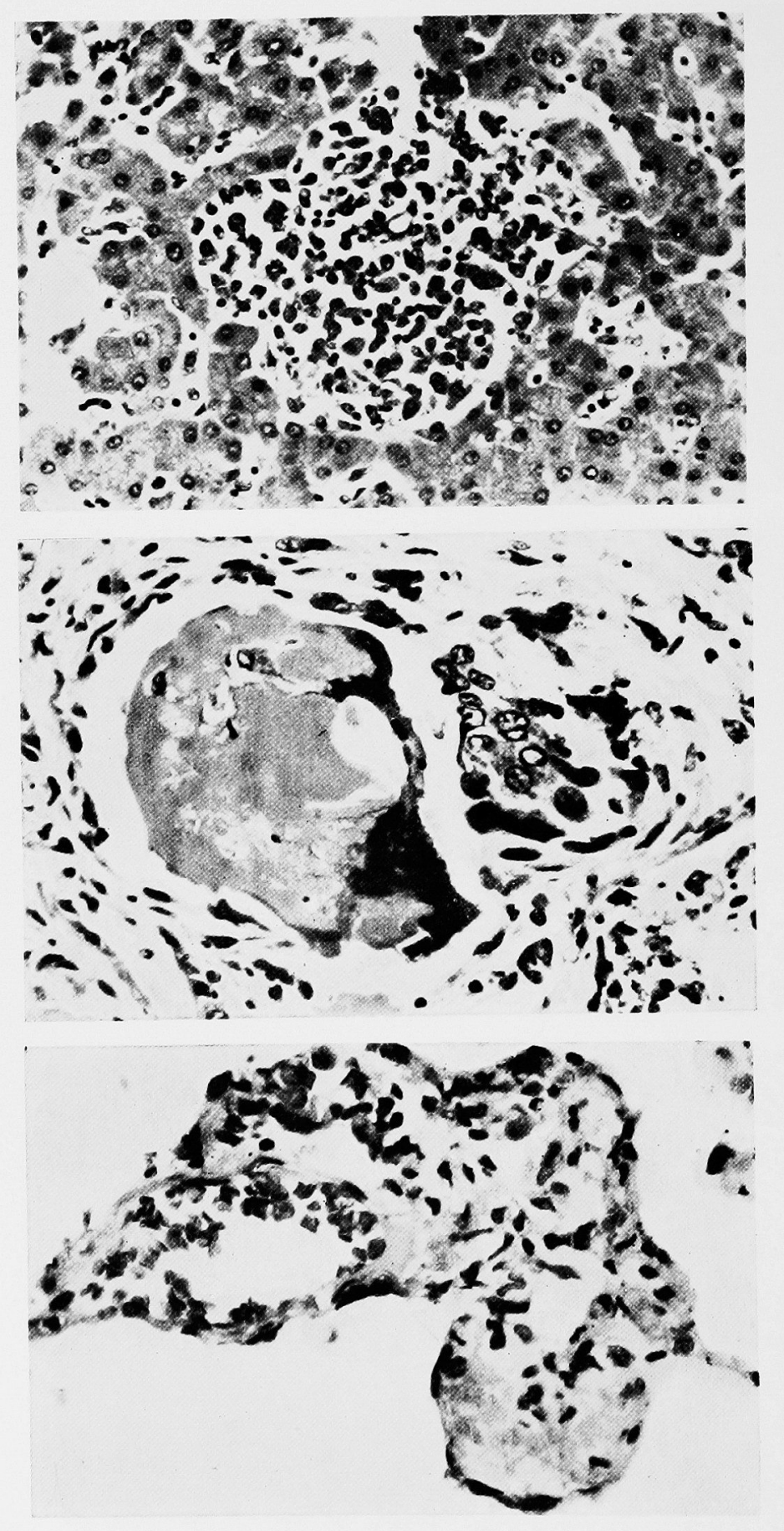

Plate VII

Plate VIII

Plate IX 

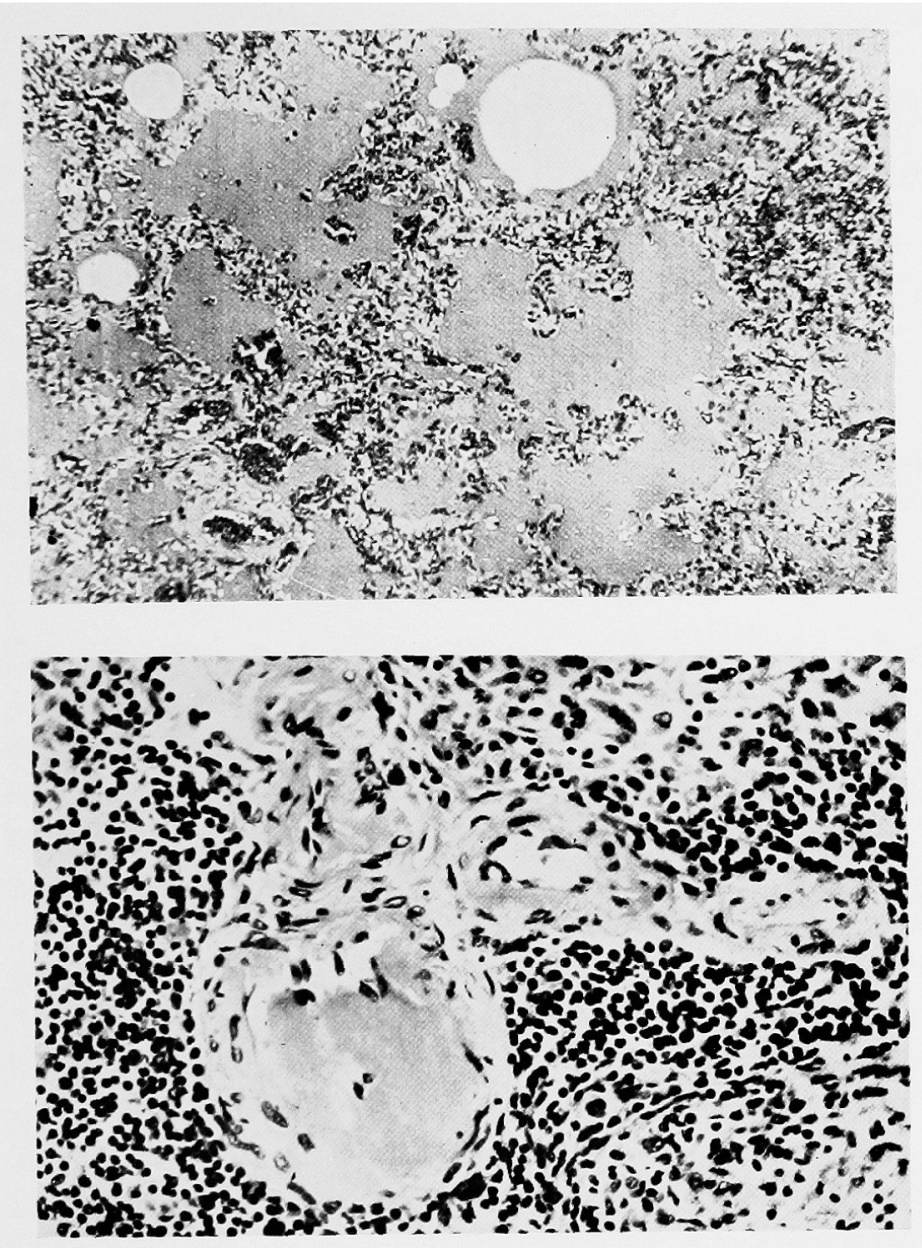

Plate X

Plate XI

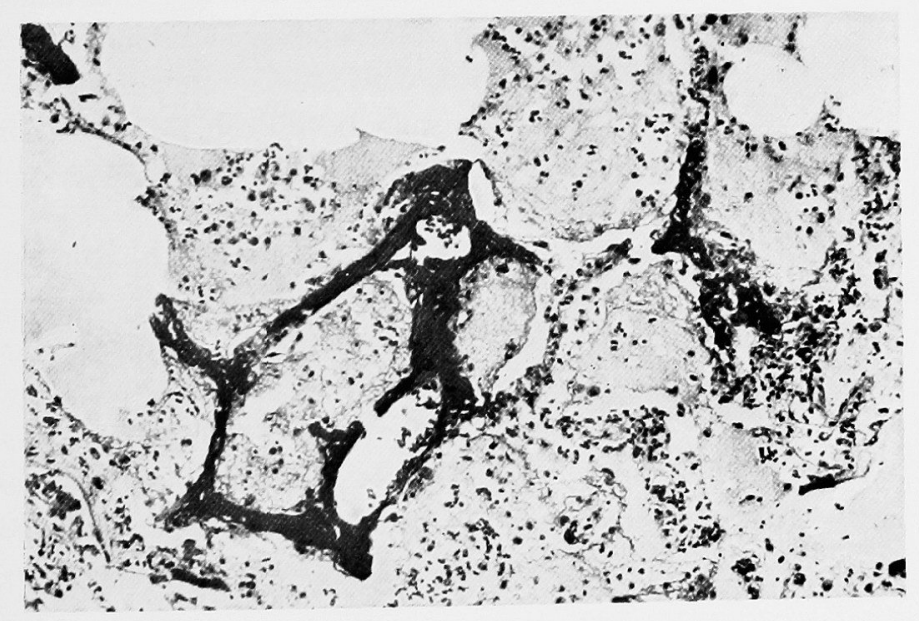

Plate XII 